Pediat. Res. 4: 337-344 (1970)

$$
\begin{array}{ll}
\text { Cystathionase } & \text { liver } \\
\text { cystathionine synthetase } & \text { methionine } \\
\text { p-hydroxyphenyl- } & \text { transsulfuration } \\
\multicolumn{1}{c}{\text { pyruvic oxidase }} & \text { tyrosinemia }
\end{array}
$$

\title{
Biochemical Observations on So-called Hereditary Tyrosinemia
}

\author{
Gerald E. Gaull ${ }^{[37]}$, David K. Rassin, Gail E. Solomon, Ruth G. Harris and John A. Sturman \\ Department of Pediatric Research, New York State Institute for Basic Research in Mental Retardation, \\ Staten Island, New York, Departments of Pediatrics and Neurology, Columbia University, \\ College of Physicians \& Surgeons, and Department of Pediatrics, Mt. Sinai Hospital School of Medicine, \\ New York, New York, USA
}

\begin{abstract}
Extract
Decreased activities of methionine-activating enzyme (ATP: L-methionine-S-adenosyl-transferase, EC. 2.5.1.6) (23 and 18 versus normal 86 nmoles product produced $/ \mathrm{mg}$ soluble protein $/ \mathrm{h}$ ) and cystathionine synthetase [30] (28 and 6 versus normal of $98 \mathrm{nmoles}$ product produced/mg soluble protein/h) in the presence of normal activity of cystathionase [30] (104 and 108 versus normal of $125 \mathrm{nmoles}$ product produced/mg soluble protein/h) were demonstrated in the liver of two patients with so-called hereditary tyrosinemia. This decreased activity also was associated with documented deficiency of $p$-hydroxyphenylpyruvic acid oxidase, tyrosine transaminase, and phenylalanine hydroxylase with values of 3 and 1.2 versus normal of 60, 2.6 and 0.8 versus normal of 20, and 3.5 versus normal of $13.7 \mu$ moles/g wet weight of liver/h, respectively (table II). In one patient, the biopsy was performed after the concentration of tyrosine in the plasma had been made normal (less than $1.0 \mathrm{mg} /$ $100 \mathrm{ml}$ ) for 3 months by dietary restriction (fig. 2). This patient has subsequently maintained normal concentrations of amino acids in the plasma on an ad libitum diet for 18 months. These findings give evidence that the abnormalities on the pathway of metabolism of methionine are independent of the abnormality in the metabolism of tyrosine and that the latter may be self-limiting in some cases (table I).
\end{abstract}

\section{Speculation}

These studies suggest that the hypertyrosinemia and the hypermethioninemia seen in so-called hereditary tyrosinemia are each nonspecific manifestations of a phenotype as yet unidentified. Whether or not methionine accumulates in the plasma in the presence of these defects in the transsulfuration pathway is probably a function of an enlarged free amino acid pool in the liver when protein synthesis in that organ is reduced.

\section{Introduction}

So-called hereditary tyrosinemia is a metabolic disease, with onset in infancy, characterized by cirrhosis, renal tubular defects, and abnormal metabolism of amino acids. The natural history of this disease can be divided into two phases: in the acute phase (often referred to as acute tyrosinosis) there is a generalized aminoacidemia with overflow aminoaciduria and progressive cirrhosis. The aminoacidemia present is a peculiar one, in that the concentrations of tyrosine and methionine in the plasma are disproportionately large. If the patient survives this first phase and passes into the second phase, the aminoacidemia is gradually 
limited to hypertyrosinemia, and sometimes to hypermethioninemia as well. The second phase is characterized by renal tubular defects, including renal aminoaciduria and loss of phosphorus with secondary rachitic changes. The second phase becomes chronic in untreated survivors, with hypertyrosinemia, tyrosyluria, and cirrhosis persisting from the first phase $[10,20]$.

In previous reports of this disorder, it has been proposed that a deficiency of $p$-hydroxyphenylpyruvic acid ( $p$ HPPA) oxidase is the specific enzymatic etiology $[8,29]$. A block at this step should result in hypertyrosinemia with increased excretion of derivatives of tyrosine (tyrosyluria), notably, $p$-hydroxyphenylpyruvic acid, $p$-hydroxyphenyllactic acid and $p$-hydroxyphenylacetic acid, as well as some tyrosine itself. The hypothesis has been advanced that this enzymatic deficiency in the metabolism of tyrosine is primary, and that the defect in the metabolism of methionine, when present, is secondary to generalized hepatic failure $[11,25]$, rather than to a deficiency or inhibition of any particular steps in the metabolism of methionine. Presumably, the accumulation of tyrosine or its derivatives interferes with the metabolism of methionine. A second hypothesis is that a specific defect in the metabolism of methionine is primary and that the changes in the metabolism of tyrosine are secondary [22]. It was later considered more likely that the primary error in tyrosinemia does not involve either tyrosine or methionine metabolism [21]. We reported results $[4,5]$ in two patients with the constellation of clinical and biochemical manifestations often referred to as hereditary tyrosinemia or tyrosinosis. Our results do not support the concept that the etiology of this disease is a specific deficiency of $p$ HPPA oxidase. It seems more likely that the decreased abilities to metabolize methionine and tyrosine are each independent, secondary manifestations of a primary phenotype, as yet unidentified. Furthermore, our observations of the clinical course of the disease suggest that the biochemical abnormalities in some cases are self-limiting. Further study of etiology and pathogenesis is warranted before unequivocal conclusions can be drawn from uncontrolled studies of the use of diets restricted in tyrosine and phenylalanine.

\section{Methods}

Analyses of amino acids [31] were performed with minor modifications of the method of SPACKMAN et al. [28]. Assay of enzymes of transsulfuration were performed according to previously published methods from this laboratory [6]. Parallel assays of some enzymes involved in the metabolism of phenolic amino acids were performed using previously published methods $[14,32]$. All other biochemical determinations were performed by standard clinical procedures [36].

\section{Case Summaries}

Patient I

The diagnosis of acute hereditary tyrosinemia was made biochemically at the age of 5 months in $E F$ when she was profoundly ill with hepatosplenomegaly, hypoglycemia, ascites, a hemorrhagic diathesis with prolonged prothrombin time, enlarged kidneys with hyperphosphaturia, hypophosphatemia, and early rachitic bone changes. The tongue was noticeably large. At this time there was a generalized hyperaminoacidemia with disproportionately high concentrations of methionine and tyrosine, but with normal concentrations of the branched-chain amino acids and also of cystine and taurine (fig. 1). The protein-bound iodine was slightly low $(3.4 \mu \mathrm{g} / 100 \mathrm{ml})$. Activity of erythrocyte galactose 1-phosphate uridyltransferase (EC. 2.7.7.10) was in the range for heterozygotes. In addition to intensive therapy with blood, albumin, diuretics, and antibiotics, she was started on a diet restricted in tyrosine and phenylalanine (research mixture $3200 \mathrm{AB}$ [33]). There was a gradual but definite change in her general clinical status; she went from a profoundly ill, pale, irritable infant, with head and hand tremors, to a responsive, alert infant. Hemoglobin returned to normal concentrations, and the hypoglycemia disappeared. Early fragmentation of the ends of the distal ulna disappeared and the size

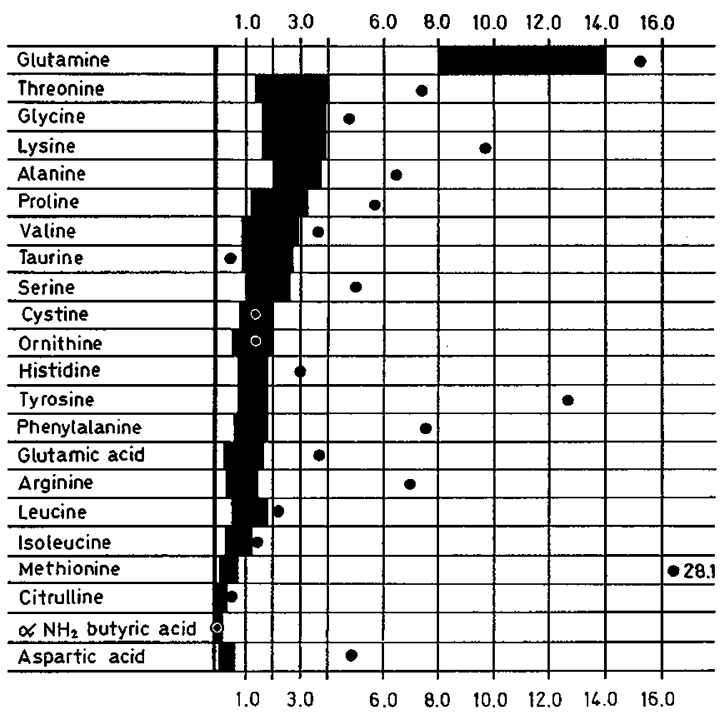

Fig.1. Initial concentrations of amino acids in the plasma in patient $I$. Values are $\mathrm{mg} / 100 \mathrm{ml}$; solid bars represent the normal range of concentration. 
of the kidneys as measured by sequential intravenous pyelography became normal. Hepatic function also improved: prothrombin time decreased, plasma proteins returned to normal, and ascites disappeared. The tongue returned to normal size. Activity of erythrocyte galactose I-phosphate uridyltransferase returned to normal.

Changes in the concentrations of methionine and tyrosine in the plasma are seen in figure 2. During the first phase of dietary manipulation (April-July), she received $3200 \mathrm{AB}$ (restricted in tyrosine and phenylalanine only) with sufficient milk to give the methionine and tyrosine intakes shown in figure 2 . The concentration of tyrosine in the plasma decreased immediately, but that of methionine remained elevated. It should be noted that her methionine intake, $80 \mathrm{mg} /$ $\mathrm{kg} / 24 \mathrm{~h}$, is not too different from the $77 \mathrm{mg} / \mathrm{kg} / 24 \mathrm{~h}$ given in a normal diet of $3.5 \mathrm{~g} / \mathrm{kg} / 24 \mathrm{~h}$ of protein, assuming an average methionine content in protein of $2-3 \%$.

At 11 months of age (July), we attempted to bring the concentration of methionine in the plasma to normal. Sobee (a formula relatively low in methionine [34]) was started, and as seen in figure 2, the concentration of methionine in the plasma decreased, but tyrosine increased. At 12 months of age (August), $3200 \mathrm{AB}$ and Sobee were used in combination; there followed a normal concentration of all amino acids in the plasma. The proportion of each dietary component was determined empirically by titration of the

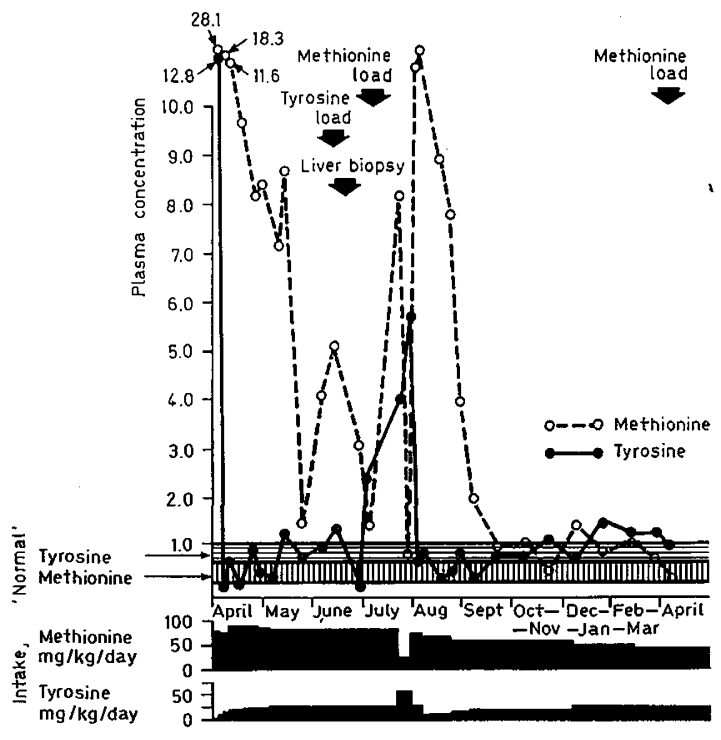

Fig. 2. Changes in the concentrations of tyrosine and methionine in the plasma with variation in their dietary intake in patient $\mathrm{I}$. Plasma values are $\mathrm{mg} / 100 \mathrm{ml}$. concentrations of tyrosine and methionine in the plasma (August-April).

At 18 months of age, she was doing well except for a low platelet count; Sobee was removed from the regimen and milk was added. At 28 months of age, $3200 \mathrm{AB}$ was gradually withdrawn and milk and meat added, so that by 29 months of age she was eating a normal diet, ad libitum. She has maintained normal concentrations of amino acids in the plasma on this diet for 18 months. Her development has been normal, and she is apparently fit, except for persistent hepatosplenomegaly.

\section{Patient II}

KS had unexplained fever at 5 days of age, abdominal distention at 5 weeks of age, and hepatosplenomegaly and hemetemesis by 8 weeks of age. Diagnosis was established at 10 weeks of age by the presence of hypertyrosinemia, tyrosyluria, and hypermethioninemia, but retrospective amino acid analysis of cerebrospinal fluid showed high concentrations of tyrosine and methionine at 8 weeks of age. The tyrosyluria was unresponsive to ascorbic acid $(275 \mathrm{mg} / 24 \mathrm{~h}$ orally for 3 days), folic acid ( $5 \mathrm{mg} / 24 \mathrm{~h}$ given intramuscularly for 3 days), and a low protein diet $(1.5 \mathrm{~g} / \mathrm{kg} / 24 \mathrm{~h}$ for 4 days). At 11 weeks of age she was started on a low methionine diet, based on the Snyderman regimen [27]. At this time, an intravenous pyelogram showed enlarged kidneys, and X-ray of long bones showed demineralization, but no rachitic changes. Three days after starting the low methionine diet the concentration of methionine in the plasma had returned to normal but tyrosine was still elevated $(5.6 \mathrm{mg} / 100 \mathrm{ml})$. Two days later she died. Acute purulent peritonitis was found at autopsy.

\section{Results}

Because the amounts of tyrosine and phenylalanine that were required to maintain normal concentrations of these amino acids in the plasma of patient $I$ were greater than expected, we questioned whether the supposed block in $p$ HPPA oxidase was complete and persistent. Oral loading tests were performed after 3 months of feeding a diet restricted only in tyrosine and phenylalanine. A load of $50 \mathrm{mg} / \mathrm{kg}$ of $\mathrm{L}$-phenylalanine demonstrated that she was able to convert phenylalanine to tyrosine (fig. 3 ) with no abnormal excretion of tyrosyl derivatives in the urine. To place the $p$ HPPA oxidase under a more direct biochemical challenge, we administered acute loads of 50 and then $100 \mathrm{mg} / \mathrm{kg}$ of L-tyrosine, but found no tyrosyluria under either circumstance and the tolerance curve was apparently normal (fig.4). A short time later, however, she was 


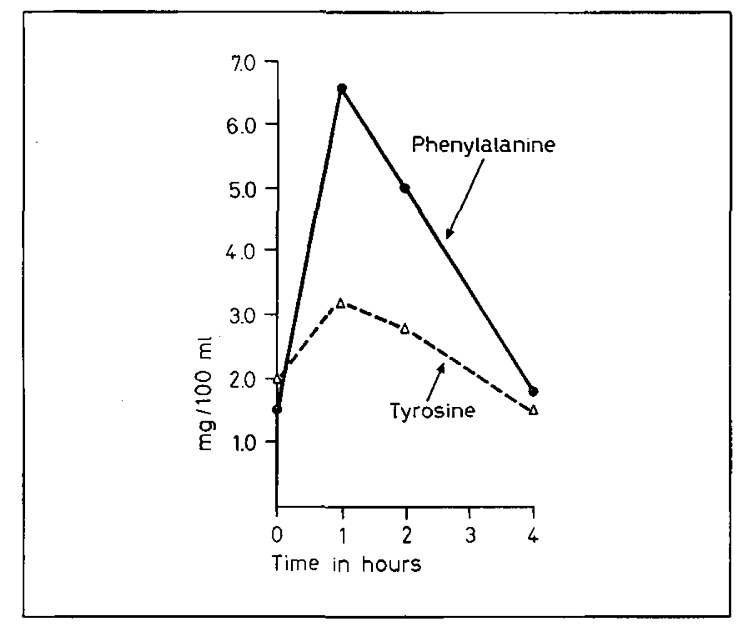

Fig. 3. Oral load of L-phenylalanine $(50 \mathrm{mg} / \mathrm{kg})$ in patient I showing normal phenylalanine tolerance and conversion to tyrosine.

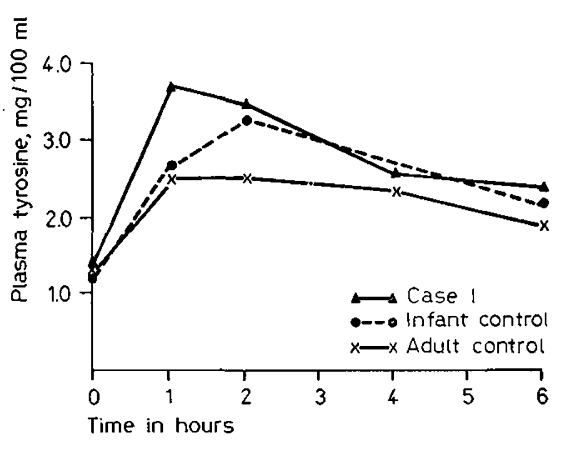

Fig.4. Oral load of L-tyrosine $(100 \mathrm{mg} / \mathrm{kg})$ in patient $I$ showing normal tolerance.

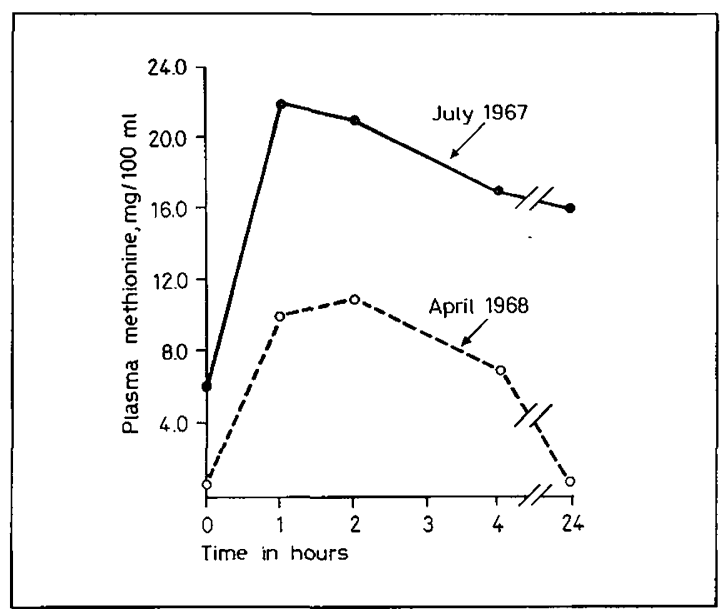

fed Sobee, unrestricted in tyrosine and phenylalanine, and she again developed hypertyrosinemia with tyrosyluria. We interpreted this to mean that the defect in the metabolism of tyrosine was still present at the time of the acute tyrosine loads but that the response to these loads was conditioned by the size of the residual pool of free tyrosine and free phenylalanine in the body.

After 3 months of feeding the first dietary regimen, which was restricted only in phenylalanine and tyrosine, and after the prothrombin time and plasma protein values had returned to essentially normal levels, an open biopsy of the liver of patient I was performed (fig.2) and samples were studied. Liver tissue from patient II, obtained $2 \mathrm{~h}$ postmortem, was similarly studied. In both patients, the specific activities of the methionine-activating enzyme and cystathionine synthetase were very low (table I). In contrast, the specific activity of cystathionase was normal in both cases. It should be noted: 1) that these results are specific activities based on milligrams of soluble protein, so are independent of the amount of insoluble fibrous tissue present in these cirrhotic livers; and 2) that in contrast to previous microassays of these enzymes [18], only the enzyme is rate-limiting, so that direct comparison of the specific activity of one enzyme to another is possible.

When patient $I$ was 9 months of age, just after the biopsy and when the concentration of methionine in the plasma was apparently decreasing, although still abnormal (fig. 2), $100 \mathrm{mg} / \mathrm{kg}$ of $\mathrm{L}$-methionine were administered orally [2]. This acute load was handled abnormally in that the concentration of methionine in the plasma did not return to original levels $24 \mathrm{~h}$

Table I. Enzymes of transsulfuration in liver from patients with acute hereditary tyrosinemia

\begin{tabular}{|c|c|c|c|c|}
\hline \multirow[t]{2}{*}{ Patient } & \multirow[t]{2}{*}{ Specimen } & $\begin{array}{l}\text { Methio- } \\
\text { nine- } \\
\text { activat- } \\
\text { ing } \\
\text { enzyme }\end{array}$ & $\begin{array}{l}\text { Cysta- } \\
\text { thionine } \\
\text { synthe- } \\
\text { tase }\end{array}$ & $\begin{array}{l}\text { Cysta- } \\
\text { thionase }\end{array}$ \\
\hline & & \multicolumn{3}{|c|}{$\begin{array}{l}\text { nmoles product produced/ } \\
\text { mg soluble protein } / \mathrm{h}\end{array}$} \\
\hline Controls $(9)$ & Biopsy & $86 \pm 16^{1}$ & $98 \pm 19^{x}$ & $126 \pm 12^{1}$ \\
\hline$I, E F$ & Open biops & sy 23 & 28 & 104 \\
\hline$I I, K S$ & $\begin{array}{l}\text { 2-h Post- } \\
\text { mortem }\end{array}$ & 18 & 6 & 108 \\
\hline
\end{tabular}

${ }^{1}$ Control values are shown \pm SEM of nine specimens.

Fig. 5. Oral loads of L-methionine $(100 \mathrm{mg} / \mathrm{kg})$ showing early abnormal methionine tolerance which was found to be normal 9 months later. 
Table II. Enzymes of tyrosine metabolism in liver from patients with acute hereditary tyrosinemia

\begin{tabular}{lccc}
\hline Patients & $\begin{array}{c}p \text { HPPA } \\
\text { oxidase }\end{array}$ & $\begin{array}{c}\text { Tyrosine } \\
\text { trans- } \\
\text { aminase }\end{array}$ & $\begin{array}{c}\text { Phenyl- } \\
\text { alanine } \\
\text { hydroxylase }\end{array}$ \\
\cline { 2 - 4 } Controls & \multicolumn{3}{c}{$\mu$ moles/g wet weight $/ \mathrm{h}$} \\
$I, E F$ & 3 & $20^{1}$ & $13.7^{1}$ \\
$I I, K S$ & 1.2 & 2.6 & 3.5 \\
\hline
\end{tabular}

${ }^{1}$ Control values are from previously published work of LADU [14].

a ter (fig. 5), as it does in normal controls [2]. In contrast to the findings in patients with homocystinuria, however, no homocystine appeared either in the plasma or the urine. The enzymatic studies offer a possible explanation. Since the activity of methionine-activating enzyme, as well as cystathionine synthetase, was low, the accumulation of homocystine would be prevented. A similar load administered after 9 months of feeding a diet relatively restricted in methionine, as well as tyrosine, was handled normally (fig. 5).

The results of enzymatic studies [32] of the same two specimens showed that the activity of $p$ HPPA oxidase was strikingly reduced ( 3 and $1.2 \mu$ moles/g wet weight of liver/h versus a control value of 60 $\mu$ moles/g wet weight of liver $/ \mathrm{h})$; the activity of tyrosine transaminase was reduced $(2.6$ and $0.8 \mu \mathrm{moles} / \mathrm{g}$ wet weight of liver/h versus a control value of $20 \mu$ moles $/ g$ wet weight of liver $/ \mathrm{h}$ ). In patient $I$, the activity of phenylalanine hydroxylase was also reduced (3.5 $\mu$ moles/g wet weight of liver/h versus a control value of $13.7 \mu$ moles/g wet weight of liver/h) (table II). Since the plasma concentration of tyrosine in patient $I$ had been normal for 3 months on a regimen restricted in tyrosine and phenylalanine, it is unlikely that the low activity of $p$ HPPA oxidase can be due to the wellknown substrate inhibition of this enzyme.

\section{Discussion}

The appearance of hypermethioninemia in acute hereditary tyrosinemia presents a problem for the $p$ HPPA oxidase-deficiency hypothesis. When first reported, hypermethioninemia was attributed to loss of functioning liver tissue. It was thought to subside after control of the tyrosinemia $[11,23,25]$. Our enzymatic studies of transsulfuration in liver give direct evidence that the decreased ability to metabolize methionine in patients with acute hereditary tyrosinemia cannot be due to loss of functioning liver tissue alone, since with such a loss all the enzymes of the pathway should be uniformly affected. On the contrary, these results sup- port the hypothesis that the decreased ability to metabolize methionine is associated with specific inhibitions or deficiencies of methionine-activating enzyme and cystathionine synthetase of the liver. These results point up that these deficiencies in the metabolism of methionine cannot be attributed to 'toxic' concentrations of tyrosine or its metabolites, since tyrosine in the plasma of patient $I$ had been reduced to normal concentrations for 3 months. These enzymatic deficiencies not only afford a reasonable explanation of hypermethioninemia, without homocystinemia, but they may also explain why cystine and taurine were not increased at a time when there was a generalized aminoacidemia (fig. 1 ). It is germane that in patient $I$ these selective deficiencies in transsulfuration enzymes were present at a time when a number of variables of liver function had improved remarkably.

Of the enzymes of the metabolism of the phenolic amino acids measured in our patients [32], pHPPA oxidase activity was the most severely affected. It is also evident, however, that compared with controls, tyrosine transaminase activity, in patients $I$ and $I I$, and phenylalanine hydroxylase activity, in patient $I$, were also decreased. Similar results from other biopsies have been reported [14] in patients when the 'biopsy' results are compared with 'biopsy' controls, rather than to 'autopsy' controls.

Doubts about the specificity of a deficiency of $p$ HPPA oxidase in the etiology of hereditary tyrosinemia were first raised by Woolf, on clinical grounds [10]. He pointed out that neonatal hypertyrosinemia, associated with immaturity of $p$ HPPA oxidase, may last as long as 2-3 months without any of the clinical stigmata associated with hereditary tyrosinemia. Infants with this temporary block in the metabolism of tyrosine have been followed prospectively and show no physical or mental impairment [17, 19]. The pathogenetic significance of $p$ HPPA oxidase deficiency was the subject of further speculation $[20,23]$; however, the first evidence that $p$ HPPA oxidase deficiency was not of primary phenotypic significance was reported by us $[4,5]$. Bodegard et al. [1], who were among the first to propose $p$ HPPA oxidase deficiency as the primary etiological factor in this disease, suggest now that all the clinical stigmata of this disease cannot be attributed to the toxic effects of the accumulation of tyrosine and related phenolic acids resulting from $p$ HPPA oxidase deficiency. They recently reported rapid progression of the disease, culminating in death, despite early institution of dietary restriction of tyrosine and phenylalanine. Furthermore, this group [7] has recently published studies of a patient with the clinical disease, who showed $p$ HPPA oxidase activity which was $25 \%$ of normal. Recently, LINDEMANN $e t$ al. [16], who also originally found evidence in favor of 
the $p$ HPPA oxidase theory have drawn attention to the fact that patients with clinical and biochemical evidence of a deficiency of liver fructose 1-phosphate aldolase, fructosemia, also show biochemical evidence of 'acute tyrosinosis', including hypermethioninemia [16]. They also interpret their findings as contrary to the $p$ HPPA oxidase hypothesis [12].

We suggest that the decreased ability to metabolize tyrosine, and the decreased ability to metabolize methionine, are independent, secondary manifestations of a primary phenotype as yet unidentified. The fact that the defect in tyrosine metabolism emerges first and persists longer [24] gives no logical credence to its causal primacy, since both may be secondary to something else, with the defect in the metabolism of methionine emerging more slowly. In fact, patient $I$ had normal concentrations of tyrosine in the plasma for 3 months during dietary restriction, and the methionine concentration remained elevated during this time. Even if the plasma methionine levels had followed suit, it would not necessarily imply a secondary relation, since it is well known that hypermethioninemia disappears spontaneously with time, if the patient survives. What has not been known until recently is that hypertyrosinemia also can disappear. We have now followed patient $I$ for 18 months on a normal diet, ad libitum, and have found normal concentrations of all amino acids in the plasma. A similar experience was reported recently from England [13]. We have also followed another child with severe metabolic cirrhosis of long duration and unknown etiology, who first developed transient hypermethioninemia and later transient tyrosinemia with tyrosyluria, but who did not run a clinical course typical of hereditary tyrosinemia. A similar conundrum was recognized by CusWORTH et al. [3].
Further evidence of the protean biochemical manifestations of this disease and their lack of specificity can be seen in the results of the measurement of the excretion of $\delta$-aminolevulinic acid and porphobilinogen by patients $I$ and $I I$, by another patient with typical acute hereditary tyrosinemia who died before he could be studied in detail, and by a patient with severe chronic 'metabolic' cirrhosis of unknown etiology with transient hypermethioninemia followed by transient hyper-

Table III. Excretion of $\delta$-aminolevulinic acid and porphobilinogen in the urine

\begin{tabular}{lccc}
\hline Patient & $\begin{array}{c}\delta- \\
\text { Amino- phobi- } \\
\text { levulinic linogen } \\
\text { acid }\end{array}$ & $\begin{array}{c}\text { Por- } \\
\text { and }\end{array}$ \\
\cline { 2 - 3 } mg/g creatinine & Diagnosis \\
\hline$I, E F$ & 0.7 & 0.1 & Acute hereditary tyrosinosis \\
$I I, K S$ & $88.3^{1}$ & 0.3 & Acute hereditary tyrosinosis \\
$H L$ & $12.1^{1}$ & 0.2 & Acute hereditary tyrosinosis \\
$R E$ & $17.5^{1}$ & $13.8^{1}$ & $\begin{array}{l}\text { Chronic 'metabolic' cirrho- } \\
\text { sis, etiology unknown }\end{array}$ \\
\hline
\end{tabular}

1 Abnormal results; range of normal values (adult) for $\delta$-aminolevulinic acid, $1.52 \pm 0.59 \mathrm{sD} \mathrm{mg} / \mathrm{g}$ creatinine; for porphobilinogen, $0.53 \pm 0.29 \mathrm{sD} \mathrm{mg} / \mathrm{g}$ creatinine (9).

tyrosinemia (table III). Professor Zetterstrom [34], whose group first reported the increased excretion of $\delta$-aminolevulinic acid, had analyses performed without knowledge of what each of the four urine specimens represented. In general agreement with their previously reported results [9], two of the three patients with typical acute hereditary tyrosinemia had increased excretion of $\delta$-aminolevulinic acid, but so did

Table IV. Enzymes of transsulfuration in liver from patients with various types of cirrhosis

\begin{tabular}{|c|c|c|c|c|c|}
\hline \multirow[t]{2}{*}{ Patient } & \multirow[t]{2}{*}{ Specimen } & $\begin{array}{l}\text { Methionine- } \\
\text { activating } \\
\text { enzyme } \\
\end{array}$ & $\begin{array}{l}\text { Cystathio- } \\
\text { nine } \\
\text { synthetase }\end{array}$ & Cystathionase & \multirow[t]{2}{*}{ Diagnosis } \\
\hline & & \multicolumn{3}{|c|}{ nmoles product produced/mg protein $/ \mathrm{h}$} & \\
\hline Controls (9) & Biopsy & $86 \pm 16^{1}$ & $98 \pm 191$ & $125 \pm 12^{1}$ & \\
\hline$Y P$ & Open biopsy & 34 & 17 & 72 & $\begin{array}{l}\text { Biliary cirrhosis with } \\
\text { cholangitis }\end{array}$ \\
\hline$D \mathcal{N}$ & Open biopsy, frozen & 18 & 30 & 114 & Biliary cirrhosis \\
\hline$C A$ & Open biopsy, frozen & 17 & 25 & 126 & Biliary cirrhosis \\
\hline$D C$ & Open biopsy & 19 & 24 & 106 & $\begin{array}{l}\text { Postnecrotic cirrhosis (?); } \\
\text { Wilson's disease }\end{array}$ \\
\hline$R E$ & Open biopsy & 11 & 19 & 151 & $\begin{array}{l}\text { Chronic 'metabolic' } \\
\text { cirrhosis-etiology } \\
\text { unknown }\end{array}$ \\
\hline
\end{tabular}

${ }^{1}$ Control values are shown \pm sEM of nine specimens. 
the patient with 'metabolic' cirrhosis of unknown etiology. The latter patient, with severe, unexplained anemia as well, also had an increased excretion of porphobilinogen. Thus, in addition to abnormal metabolism of tyrosine, methionine, galactose, and fructose, porphyrin metabolism must be added to the growing list of biochemical responses of a sick liver.

The liver has a finite number of ways to respond (i.e., hypoprothrombinemia, hyperbilirubinemia, hypoalbuminemia) to a variety of etiologically distinct diseases. It seems likely that functional deficiencies in the enzymatic activities governing the metabolism of tyrosine and methionine are among these responses. To test this hypothesis, we have examined the same enzymes of transsulfuration in liver specimens available to us from a few unselected patients with cirrhosis. All showed the same pattern that appeared in hereditary tyrosinemia (table IV). The enzymes of tyrosine metabolism were not studied in the biopsies from these patients with other types of cirrhosis. LEVINE and CoNN [15], however, have recently provided considerable evidence for defective metabolism of tyrosine in a variety of diseases of the liver accompanied by cirrhosis.

The question arises why only some patients with liver disease develop hypermethioninemia, since the pattern of reduction in transsulfuration activity is not specific for hereditary tyrosinemia. The amount of methionine usually presented to the liver during the course of a day, and the amount of soluble protein in the liver can be calculated from the in vitro activities of these enzymes; normally there is about a thousand times as much enzyme at any one time as is needed to handle the substrate. Thus, for an increase in the size of the pool of free methionine to occur without a virtually complete enzymatic block, two events would seem to be required: 1) partial reduction in enzymatic activity for utilization of methionine; and 2) decreased rate of utilization of amino acids generally, such as would be expected with the failure in synthesis of protein that accompanies hypoalbuminemia.

Since the etiology and pathogenesis of this heritable disease are incompletely understood and its clinical course is uncertain, and in some cases apparently selflimiting, caution is urged in the interpretation of exiguous results from uncontrolled studies of dietary treatment.

\section{Summary}

Decreased activities of some of the enzymes of transsulfuration and of the metabolism of phenolic amino acids in the liver of patients with so-called hereditary tyrosinemia suggest: a) This disease is not due to a specific deficiency of $p$-hydroxyphenylpyruvic acid oxidase. $b$ ) Hypermethioninemia, when accompanying this disorder, is not due to a diffuse loss of functioning liver tissue nor to toxic concentrations of tyrosine, but rather is associated with decreased activities of methionine-activating enzyme and cystathionine synthetase in a liver with an enlarged pool of free methionine. Clinical and metabolic observations, as well as the enzymatic studies, suggest that both the hypertyrosinemia and the hypermethioninemia are unspecific manifestations of a phenotype not yet identified.

\section{References and Notes}

1. Bodegard, G.; Gentz, J.; Lindblad, B.; LindSTEDT, S. and ZetTerstrom, R. : Hereditary tyrosinemia. III. On the differential diagnosis and the lack of effect of early dietary treatment. Acta paediat. scand. 58: 37 (1969).

2. Brenton, D.P.; Gusworth, D.C. and Gaull, G.E.: Homocystinuria: Metabolic studies on 3 patients. J. Pediat. 67: 58 (1965).

3. Cusworth, D.G.; Dubowitz, V. and Harvey, C. C.: Hypermethioninemia in acute tyrosinosis. Lancet $i$ : 598 (1966).

4. Gaull, G.E.; Harris, R. C. and Solomon, G.: Tyrosinosis: Biochemical and dietary studies. Pediat.Res. 2: 403 (1968).

5. Gaull, G. E.; Rassin, D.K. and Sturman, J.A.: Significance of hypermethioninemia in acute tyrosinosis. Lancet $i$ : 1317 (1968).

6. Gaull, G.E.; Rassin, D.K. and Sturman, J.A.: Enzymatic and metabolic studies of homocystinuria: Effects of pyridoxine. Neuropädiatrie 1: 199 (1969).

7. Gentz, J.; Heinriah, J.; Lindblad, B. ; Lindstedt, S. and Zetterstrom, R.: Enzymatic studies in a case of hereditary tyrosinemia with hepatoma. Acta paediat. scand. 58: 393 (1969).

8. Gentz, J.; Jagenburg, R. and Zetterstrom, R.: Tyrosinemia: An inborn error of tyrosine metabolism with cirrhosis of the liver and multiple renal tubular defects (de Toni-Debre-Fanconi syndrome). J.Pediat. 66: 670 (1965).

9. Gentz, J.; Johansson, B.; Lindblad, V.; LindSTEDT, S. and ZETTERSTROM, R.: Excretion of deltaamino-levulinic acid in hereditary tyrosinemia. Clin. chim. Acta 23: 257 (1969).

10. Gjessing, L. R.: Symposium on tyrosinosis (Scandinavian University Books, Oslo 1966).

11. Gjessing, L. R. and Halvorsen, S. : Hypermethioninemia in acute tyrosinosis. Lancet $i i: 1132$ (1965).

12. Halvorsen, S. and Gjessing, L.: Studies on the amino acid levels in serum and urine of infants and children with metabolic liver diseases (Abstract). Pediat. Res. 4: 215 (1970).

13. Harries, J.T.; SEAKIns, J.W.T.; ERSSER, R.S. and LLOYD, J.K.: Recovery after dietary treatment of 
an infant with features of tyrosinosis. Arch. Dis. Childh. 44: 258 (1969).

14. LADu, B. N. : The enzymatic deficiency in tyrosinemia. Amer.J. Dis. Child. 113: 54 (1967).

15. Levine, R.J. and Conn, H.O.: Tyrosine metabolism in patients with liver disease. J.clin. Invest. 46: 2012 (1967).

16. Lindemann, R.; Gjessing, L.R.; Merton, B. and Halvorsen, S.: Fructosaemia 'acute-tyrosinosis'. Lancet $i$ : 891 (1969).

17. Menkes, J.H.; Ghernick, V. and Ringel, B.: Effect of elevated blood tyrosine on subsequent intellectual development of premature infants. J.Pediat. 69: 583 (1966).

18. Mudd, S.H.; Finkelstein, J.D.; Irreverre, F. and LAster, L.: Transsulfuration in mammals, microassays and tissue distributions of three enzymes of the pathway. J. biol. Chem.240:382 (1965.)

19. Partington, M.W.; Delahaye, D.J.; Masotti, R.E.; ReaD, J.H. and Roberts, B.: Neonatal tyrosinaemia: A follow-up study. Arch. Dis. Childh. 43: 195 (1968).

20. Partington, M.; Sariver, C.R. and Sass-KortSAK, A.: Conference on hereditary tyrosinemia. Canad. Med. Ass. J. 97: 1045 (1967).

21. Perry, T.L.: Tyrosinemia associated with hypermethioninemia and islet cell hyperplasia. Canad. med. Ass. J. 97: 1067 (1967).

22. Perry, T.L.; Hardwick, D.F.; Dixon, G.H.; Dolman, C. L. and Hansen, S.: Hypermethioninemia: A metabolic disorder associated with cirrhosis, islet cell hyperplasia, and renal tubular degeneration. Pediatrics 36: 236 (1965).

23. Scriver, C.R.: The phenotypic manifestations of hereditary tyrosinemia and tyrosyluria: a hypothesis. Canad. med. Ass.J. 97: 1073 (1967).

24. Sariver, G.R.: Significance of hypermethioninemia in acute tyrosinosis. Lancet $i$ : 1319 (1968).

25. Scriver, C.R.; Glow, G. L. and Silverberg, M. : Hypermethioninemia in acute tyrosinosis. Lancet $i$ : 1153 (1966).

26. Scriver, C.R.; Larochelle, J. and Silverberg, M. : Hereditary tyrosinemia and tyrosyluria in a French Canadian geographic isolate. Amer.J. Dis. Child. 113: 41 (1967).

27. Snyderman, S.E.: The therapy of maple syrup urine disease. Amer. J. Dis. Child. 113: 68 (1967).

28. Spackman, D.H.; Moore, S. and Stein, W.H.: Automatic recording apparatus for use in the chromatography of amino acids. Analyt. Chem. 30: 1190 (1958).

29. Taniguchi, K. and Gjessing, L.R.: Studies on tyrosinosis. 2. Activity of the transaminase, parahydroxyphenyl-pyruvate oxidase, and homogentisic acid oxidase. Brit. med.J. i: 968 (1965).
30 . In the text synthetase is used. We prefer cystathionine synthase, EC. 4.2.1.21 (listed in the Report of the Commission on Enzymes of the International Union of Biochemistry 1961) rather than the recommended L-serine hydro-lyase, EC. 4.2.1.13 (serine dehydratase) or L-threonine hydro-lyase, EC. 4.2.1.16 (threonine dehydratase) since there is considerable evidence that it is a separate enzyme (Brown, F. G.; Mallady, J. and Roszell, J.A.: The separation of rat liver serine dehydratase and cystathionine synthase. J.biol. Chem. 241: 5220 [1966]; Nakagawa, H. and Kimura, H.: Purification and properties of cystathionine synthetase from rat liver: Separation of cystathionine synthetase from serine dehydratase. Biochem. biophys. Res. Commun. 32: 208 [1968]; Frnkelstein, J. D. : Methionine metabolism in mammals. Effects of age, diet and hormones on three enzymes of the pathway in rat tissues. Arch. Biochem. Biophys. 122: 583 [1967]). Cystathionase has been used rather than L-homoserine hydro-lyase (deaminating), EG. 4.2.1.15, since it is the transsulfuration function we are studying, and we are not convinced that these two functions are mediated by the same enzyme.

31. Model nos. 116 or $120 \mathrm{C}$, Beckman Instruments, Inc., Spinco Division, Palo Alto, CA.

32. We thank Dr. B.LADu for his help in running parallel assays of the enzymes studied.

33. Mead Johnson Company, Evansville, IN.

34. Mead Johnson Company.

35. We thank Dr. R. ZetTERSTROM for analyzing urine specimens.

36. Supported in part by the New York State Department of Mental Hygiene and National Institute for Neurological Diseases and Blindness Grant no. NB-03359. Dr. Solomon was the recipient of National Institute for Neurological Diseases and Blindness. Training Grant no.1-F-11-NB 1567-01NSRA. Informed consent was obtained in accordance with the provisions set forth in the Declaration of Helsinki.

37. We are grateful to Professors B. LADu and R.ZETTERSTROM for the use of their data; to them and Drs. S. Halvorsen, L. GJessing, and J.Gentz for their helpful discussion of the manuscript; to Dr. Donald Gribetz who referred patient $I$ to us, and assisted in her clinical management; and to Miss JudrTH Poje for expert technical assistance.

38. Request for reprints should be addressed to: Gerald E. Gaulx, M.D., Institute for Basic Research in Mental Retardation, 1050 Forest Hill Road, Staten Island, NY 10314 (USA).

39. Accepted for publication December 16, 1969. 